\title{
Giant omphalocele: current perspectives
}

\author{
This article was published in the following Dove Press journal: \\ Research and Reports in Neonatology \\ 18 July 2016 \\ Number of times this article has been viewed
}

\section{Alexander Josef Mack' \\ Bjarte Rogdo ${ }^{2}$ \\ 'Department of Pediatric Surgery, ${ }^{2}$ Pediatric and Neonatal Intensive Care Unit, Children's Hospital of Eastern Switzerland, St Gallen, Switzerland}

\begin{abstract}
Giant omphalocele (GO) is a congenital ventral abdominal wall defect characterized by a large opening with herniated abdominal organs, including liver, loss of abdominal cavity volume, and other associated congenital anomalies. Treatment of patients with GO represents a major challenge for involved caregivers. Despite significant improvements in neonatal intensive and surgical care over the last decades, the condition is still associated with high mortality rates and a high risk of severe morbidity in survivors. The principles of the earliest attempts to treat GO surgically and conservatively are still easily recognized in the main approaches used today. In this review, we discuss the more recent developments in the treatment of GO, including perioperative management and associated morbidities of the condition.
\end{abstract}

Keywords: giant omphalocele, abdominal wall closure, staged repair, delayed repair

\section{Introduction}

An omphalocele is a midline ventral abdominal wall defect with herniation of abdominal viscera into a membrane-covered sac consisting of an inner peritoneal layer and an outer layer of amnion. The incidence is estimated at one in 6,000 live births. ${ }^{1}$ Although no universal consensus on the definition exists, some authors consider the malformation to be a giant omphalocele (GO) when the abdominal wall defect exceeds 5-6 cm in diameter and the sac contains the whole or most of the liver. ${ }^{2}$ This definition has drawbacks. An omphalocele containing large amounts of liver and/or intestine but with a smaller abdominal wall defect does not fall under this definition, although a primary reposition may not be possible. The definition does not take into account the size of the infant, and the size of the sac itself may also be variable, depending on the state of the child (crying, sleeping, etc) due to variability in intra-abdominal pressure.

In early first trimester, there is a physiological herniation of intestines into the umbilical cord. If the herniated intestines fail to return to the abdominal cavity between 6 weeks and 10 weeks of gestation, an omphalocele occurs. ${ }^{3,4}$ Therefore, prenatal diagnosis may be made late in first trimester, although it is more common to diagnose the condition on routine scan around 18-20 weeks of gestation. ${ }^{5}$ The reported incidence in early pregnancy is much higher than at birth due to both spontaneous intrauterine fetal death and pregnancy termination. ${ }^{6,7}$

The operative treatment of GO and perioperative care of these patients represents a major challenge for the involved caregivers. GO is associated with lung hypoplasia, pulmonary hypertension, other major malformations such as congenital heart defects,
Correspondence: Bjarte Rogdo Care Unit Children's Hospital of Eastern Switzerland, Claudiusstrasse 6 9006 St Gallen, Switzerland

$\mathrm{Tel}+4$ I $7 \mid 2431952$

Email bjarte.rogdo@kispisg.ch 
and chromosomal aberrations. The postoperative period is often complicated by abdominal hypertension. The rate of lung hypoplasia in a GO lies between $54 \%$ and $70 \%$, with mortality rates reaching $30 \%-46 \%{ }^{8,9}$

Whenever possible, primary surgical closure is the method of choice in treating these patients. There have been attempts in predicting feasibility of primary closure based on ratios of omphalocele diameter to biometric measures in prenatally diagnosed exomphalos. ${ }^{10}$ Even though ratios between volume of herniated organs and size of abdominal cavity might be helpful, other authors suggest that only an attempt of primary closure will show if this is possible or not. ${ }^{11}$ In a retrospective analysis, Fawley et al calculated omphalocele ratio defined as omphalocele diameter/abdominal circumference in 30 neonates with omphalocele and available prenatal ultrasound scans. In $60 \%$ (12/20) of the patients with a ratio $<0.26$, primary surgical closure was achieved, compared to none in the group with a ratio $>0.26$. Duration of mechanical ventilation was significantly prolonged in the high-ratio group. ${ }^{12}$ Reduction of a large omphalocele with a mismatch in volume of herniated organs and size of abdominal cavity may lead to an abdominal compartment syndrome (ACS) due to elevated intra-abdominal pressure with respiratory insufficiency, acute renal failure, hypotension, and intestinal ischemia. $^{13}$

If the primary closure fails or is not feasible, the two main alternatives are staged repair and conservative treatment with delayed closure. There exist several possible techniques in each group, however, with no leading, preferred method. This was emphasized in the study of van Eijck et al. ${ }^{14}$ Authors of publications (1967-2009) on operative techniques for GO were asked if their published techniques were still in use in their own center. Almost half of the authors had changed or stopped using the technique after publication, but the change was not to a particular proven better technique. This indicates that there is no general preferred method of treatment for GO and that an individualized approach is often taken. In this article, we present an overview of the past and current techniques used in treating GO, and we briefly discuss the perioperative care and associated morbidities of the condition.

\section{Postnatal considerations}

Most infants with a GO require admission to a neonatal intensive care facility after birth due to respiratory insufficiency. In a recently published retrospective analysis, Baerg et $\mathrm{al}^{15}$ confirmed respiratory insufficiency at birth and pulmonary hypertension between 2 days and 7 days after birth to be significant independent factors associated with increased mortality. Depending on the level of respiratory support, an infant could be too instable for surgical intervention. ${ }^{16}$ In a setting of severe pulmonary compromise and extreme prematurity, further treatment might even be considered futile. Feltman et $\mathrm{al}^{17}$ addressed these issues in a recent publication. It is important to discuss prognosis with parents. If chances of survival or survival without severe morbidity are considered very low, the option of redirection to palliative care could be appropriate; in such a setting, it might be helpful to involve a clinical ethicist.

GO represents a condition with high rates of morbidity and mortality. Danzer et $\mathrm{al}^{1}$ reported severe delays for cognitive, language, and motor outcomes in $40 \%$ of patients with GO examined at a median age of 12 months. The mortality rate was $20 \%$ in this small collective. Considerably higher rates of mortality and poor neurodevelopmental outcome must be expected when GO is complicated with pulmonary hypoplasia, prematurity, and other malformations. Hence, a thorough search for associated anomalies should be undertaken, including echocardiography and cerebral and abdominal ultrasound. A genetic workup is justified in most cases. Pacilli et $\mathrm{al}^{2}$ reported associated malformations in up to $50 \%$ of infants with GO. Risk factors that correlate with poor outcome are large size of defect, rupture of omphalocele sac, low birth weight, low gestational age, additional malformations, and lung hypoplasia. ${ }^{18}$ There might be an association between defect size and type of additional malformation. Kumar et $\mathrm{al}^{19}$ found intestinal malformations frequently associated with defects $<4 \mathrm{~cm}$, whereas cardiac malformations were seen more often in defects $>4 \mathrm{~cm}$.

\section{Surgical options}

As already mentioned, the three existing surgical options are primary, staged, and delayed repair. If primary repair is not feasible, there is no consensus concerning the best next step. The available literature largely consists of small caseseries. Randomized, controlled studies comparing techniques are lacking. Hence, there is low-level evidence on which approach to take. In low-income countries, resources and availability of intensive neonatal care might also affect the decision on which treatment to choose..$^{20,21}$

\section{Primary repair}

Primary repair comprises the reposition of the herniated viscera, resection of the cele wall, and repair of the abdominal layers including the fascia. Advantages are a low infection rate and good chances of early enteral feeding. ${ }^{18}$ A major 
disadvantage is the high risk of ACS. The postoperative monitoring should include regular measurements of intraabdominal pressure. Intravesical pressure is used as a substitute for direct measurement of intra-abdominal pressure, and it can be measured through a urinary catheter after installation of normal saline $(1 \mathrm{~mL} / \mathrm{kg}){ }^{22}$ In addition, clinical signs of $\mathrm{ACS}$, such as increasing respiratory insufficiency and renal failure, must be sought. The association between elevated intra-abdominal pressure and anuria is well documented. ${ }^{13}$ Some authorities suggest intraoperative stretching of the abdominal wall and emptying of intestinal content (meconium) by squeezing the intestine intraoperatively, but these methods are controversial. ${ }^{23}$

\section{Staged repair}

Staged repair includes measures to enhance the volume of the abdominal cavity before closing the abdominal wall as well as closing the abdominal wall in several steps.

The planned hernia was first described by Gross in $1948 .{ }^{24}$ A ventral hernia is created as skin closure is attempted over the amnion sac without reduction of omphalocele content. In most cases, secondary definitive closure was accomplished within 6-24 months after primary surgery. Then the question emerges whether a fascial closure is possible with or without a fascial substitute. The sac can be resected or left intact. If the sac is adhesive to the liver, it might have to be left intact. Avoiding manipulation of the intestine will reduce the risk of adhesions and infections, but the mandatory intestinal rotational anomaly will be left untouched. ${ }^{2}$

The Schuster bag was introduced in 1967. Schuster used the method in eleven patients of whom nine survived. ${ }^{25}$ The amnion sac is resected, and a polytetrafluoroethylene reinforced sac is fixated to the fascial margin of the defect and suspended above the patient. A partial-to-complete reposition of the herniated viscera results due to gravity. During the course of the next few days, the size of the bag can be reduced. This method leads to a gentle, stepwise reduction of viscera, minimizing the risk of a sudden increase in intra-abdominal pressure and ACS, entities both described by Schuster. This new method was met with initial skepticism, but some years later, its groundbreaking advantages were recognized, including improved survival rates of up to $90 \% .^{23}$ Over the years, the technique has experienced minor modifications. In 1969 , Allen and Wrenn proposed the utilization of Silastic ${ }^{\circledR}$ bag (Dow Corning Corporation, Auburn, MI, USA). ${ }^{26}$ Risk of infection, suture breakdown, dehiscence, and emergence of enterocutaneous fistula are considered disadvantages of this technique. In addition, time necessary to gain the abdominal cavity volume is difficult to predict. ${ }^{18,27,28}$ Hong et al ${ }^{29}$ introduced sequential ligation of the sac to reduce its volume for a quicker reduction of herniated content. Risby et $\mathrm{al}^{30}$ evaluated Gore ${ }^{\circledR}$ Dualmesh (Gore, Flagstaff, AZ, USA) in staged repair of abdominal wall defects in a recently published article. Over an 18-year period, Gore Dualmesh was used in 34 patients (27 with gastroschisis and seven with omphalocele), and mesh-related complications were seen in $15 \%$ of the patients (four with detachment of mesh and one with ACS). The main advantage according to the authors is the possibility to obtain tension on the fascial edges, avoiding lateralization, which is a problem with the Silastic silo method. When secondary fascial closure is impossible, the mesh may be left in situ to support the build-up of fibrous tissue beneath the mesh, allowing for epithelialization or skin grafting after removal.

Brown et $\mathrm{al}^{31}$ described the technique of external compression in case of unruptured exomphalos with delayed closure (Delayed External Compression Reduction of Omphalocele). The omphalocele was bandaged under sterile precautions with mild compression and suspension to enable spontaneous reposition. All patients had herniation of liver. Definitive abdominal wall closure was facilitated after 5-6 days. The authors found this method a reasonable alternative to the Silo technique as it requires only one operation, and secondary silo-associated complications could theoretically be avoided.

In placing tissue expanders inside the abdominal cavity or in the subcutaneous or intermuscular layer, a slow increase of the abdominal capacity can be accomplished. One of the advantages compared to silo bag is the avoidance of mechanical pressure on viscera. It also allows for a more precisely controlled increase in intra-abdominal pressure. ${ }^{32}$ Martin et al implanted an intra-abdominal tissue expander via Pfannenstiel incision without resection of the cele wall in a newborn baby. In a second child, a tissue expander was implanted laparoscopically after conservative treatment of the GO. ${ }^{33}$ De Ugarte et al emphasized the risk of an uncontrolled increase in intraabdominal pressure that could compromise pulmonary and renal function. Also there is a risk of kinking of the mesenteriali vessels that could lead to intestinal ischemia. Therefore, the authors support the concept of implanting the expander device in the abdominal wall rather than intra-abdominally. ${ }^{34}$

If fascial closure is still not possible, tissue expansion substitutes can be used to close or bridge the fascial defect. Materials can be artificial (eg, Gore-Tex ${ }^{\mathrm{TM}}$ [W.L. Gore \& Associates, Inc. Newark, DE, USA], Prolene-mesh ${ }^{\mathrm{TM}}$ [Ethicon, Inc. Somerville, MI, USA]) or biological (eg, bovine acellular pericard patch). ${ }^{14}$ They bear the risk of infection with the necessity of removal. Some products are 
biodegradable. Long-term studies concerning stability and outcome are lacking. ${ }^{35}$

Acellular dermal matrices are a group of materials that are used in a broad variety of indications in the field of reconstructive surgery. It provides a collagen matrix to facilitate the migration of own soft tissue cells. The available products are of biological origin (allograft or xenograft: porcine/bovine). Additional skin coverage after growing-in is possible but not mandatory. There are a few reports that document the use of this relatively new technique in the treatment of ventral abdominal defects such as GO. A disadvantage is the high costs of these materials. ${ }^{36-40}$

Component separation technique (CST) was first described by Ramirez in 1990. This technique offers the opportunity of a fascial closure without artificial material. ${ }^{41}$ The approximation of the rectus sheets is facilitated by longitudinal incision of the external oblique muscle fascia and separation of the internal and external oblique muscle in the avascular plane between the two muscles. Van Eijck et al used this technique in ten patients and gained an abdominal wall closure in all their patients without artificial material. ${ }^{42,43}$ In a randomized controlled trial, 19 patients treated with CST were compared to 18 patients treated with a prosthetic patch (polytetrafluoroethylene). ${ }^{40}$ The CST group showed a high relapse rate of $52 \%$ compared to $22 \%$ in the patch group, but infection led to removal of the patch in $38 \%$.

The use of a vacuum-assisted closure device is described in some cases. ${ }^{38,44}$ Suction level was $50-75 \mathrm{mmHg}$; change of the wound dressing was carried out every 3-5 days. To protect the intestine from the sponge, a nonadhesive sheet is necessary. The definitive wound closure was facilitated via skin transplantation (full thickness/split thickness).

Baird et $\mathrm{al}^{28}$ described the use of a dynamic wound closure system (ABRA device ${ }^{\circledR}$, Canica, Ontario, Canada) in a 34-week-old baby after having to leave the abdomen open due to evolving ACS. The authors initially used a silastic bag, but the sutures were torn out of the fascia. After application of the dynamic wound closure system, a relevant reduction of the defect size was accomplished within 3 weeks. Definitive repair was facilitated via CST.

\section{Delayed repair}

This old-established technique has regained popularity over the last two decades. The delayed repair consists of promoting escharization and spontaneous epithelialization of the cele sac and avoiding infection of the sac. Therefore, the sac is typically desiccated, and substances to promote escharization are applied. Advantages are avoidance of surgery in the neonatal period, intestine is left untouched, and early enteral feeding is usually possible. ${ }^{14}$

Especially infants with severe pulmonary compromise, premature infants, or others who do not tolerate an increase in abdominal pressure might profit from this method. ${ }^{26}$ It is often used in resource-limited areas where the possibility of neonatal intensive care is limited. Disadvantages are potentially long hospital stays and risk of infection. Correction of the resulting ventral hernia can be difficult because the intra-abdominal volume may not increase at the same rate as the viscera prior to definitive closure. ${ }^{26,35}$ To facilitate escharization and prevent infection, the utilized substances should have an antiseptic function. The possibility of absorption and accumulation of potentially toxic agents due to the large surface area is of concern. Various substances have been used for this purpose. Among the first documented to be used for this purpose are alcohol, mercury, and silver nitrate. ${ }^{45,46}$ These were of course abandoned due to toxicity. ${ }^{47}$ Application of iodine is still used but controversial because of risk of iodine-induced thyroid dysfunction. Silver sulfadiazine may cause allergic reactions, methemoglobinemia, hemolysis, and argyria. ${ }^{48,49}$

The antimicrobial effect of povidone-iodine is excellent and better compared to silver sulfadiazine. Therefore, it was widely used in the conservative treatment of omphalocele. The major disadvantage is the risk of inducing thyroid dysfunction due to absorption of iodine. Whitehouse et al reported six neonates with omphalocele treated with application of povidone-iodine, five patients with $2.5 \%$, and one patient with $1 \%$ solution. All patients showed transient elevation of thyroid-stimulating hormone levels, which normalized spontaneously. One child remained hypothyroid but was later diagnosed to have a congenital hypothyroidism. ${ }^{48}$

Pandey et $\mathrm{a}^{50}$ followed 25 newborns treated with 5\% povidone-iodine solution combined with an antibiotic powder (polymyxin B sulfate, bacitracin zinc, and neomycin). Duration of application was $12.34 \pm 2.12$ days. Thyroid parameters were measured until day 10 and showed normal levels. Escharization was faster compared to povidone-iodine alone, and no dressing was necessary. Application without dressing might have influenced the amount of iodine absorbed in these cases.

Silver sulfadiazine is a well-known agent in the treatment of burns. It is low priced, enables a moist environment that facilitates wound healing, and is microbicidal. Several studies verified the effectiveness of silver sulfadiazine in the treatment of omphalocele. ${ }^{8,9}$ In a paper published by Lee et al, ${ }^{18} 22$ omphalocele patients were conservatively treated by application with silver sulfadiazine. Median time to start enteral feeding was 4 days (range 1-19 days), and 


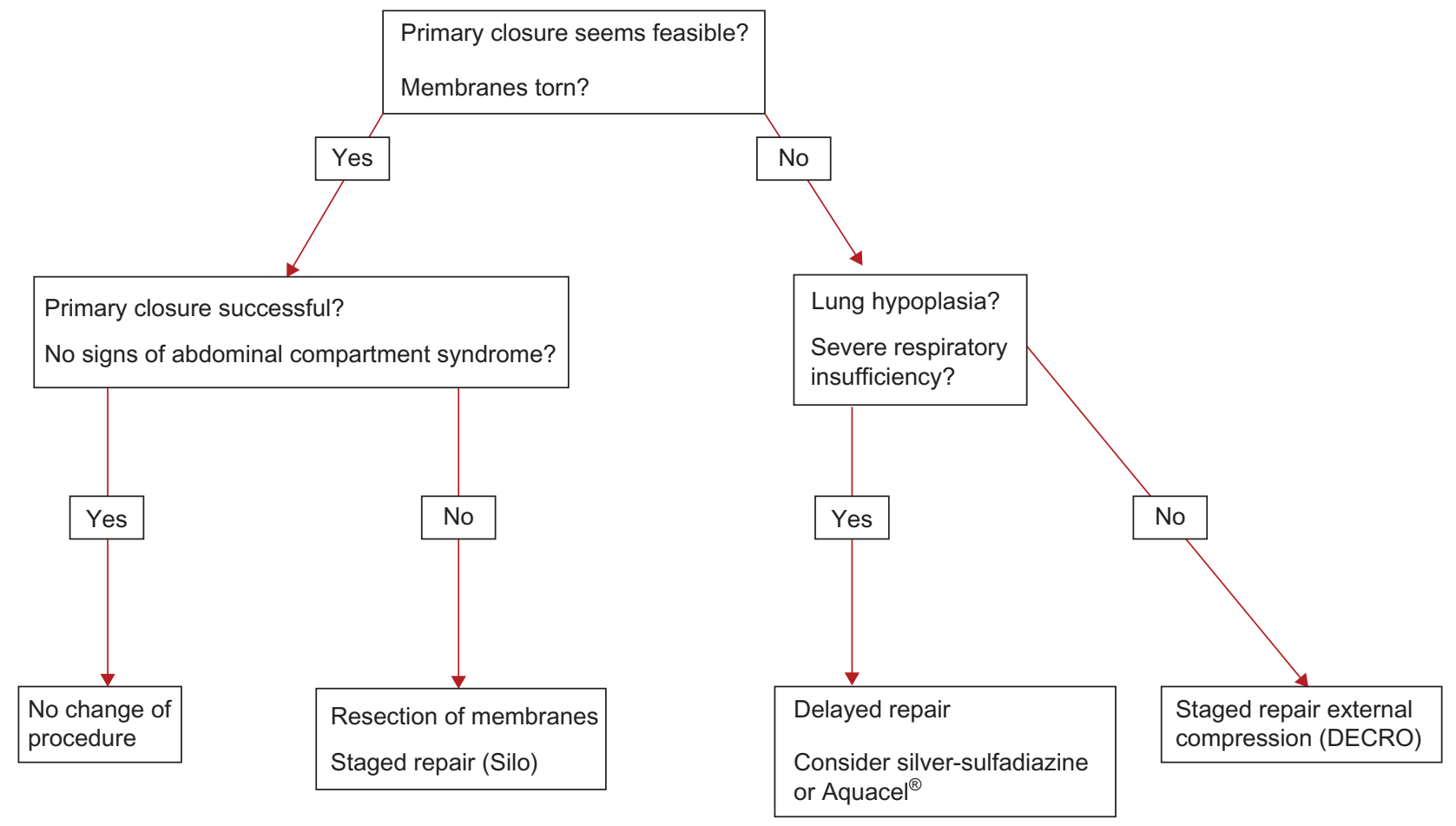

Figure I Schematic overview over considerations necessary in deciding what approach to take when facing a baby with a giant omphalocele. Abbreviation: DECRO, delayed external compression reduction of an omphalocele.

median length of stay was 20 days (range 5-239 days). No complications were seen. Nuchtern et $\mathrm{al}^{26}$ compared 15 patients with staged repair (silobag) to seven patients with conservative treatment (silver sulfadiazine application). The silver sulfadiazine group was superior regarding length of stay ( 22 days vs 42 days) and time to start enteral feeding ( 6 days vs 35 days). In none of the above-mentioned studies, silver serum concentration was measured. Lewis et a ${ }^{49}$ found alarming high blood levels of silver that normalized spontaneously after cessation of the silver sulfadiazine application. No child showed signs of a silver intoxication. Nevertheless, the authors advised against the use of silver sulfadiazine.

As an alternative to the established conservative treatment options, Almond et al proposed the use of a silverimpregnated antimicrobial dressing (Aquacel ${ }^{\circledR} \mathrm{Ag}$, ConvaTec Inc.). It was used as a primary dressing in a patient with GO. Secondary dressing was polyurethane foam with silicone layer (Mepilex ${ }^{\circledR}$, Mölnlycke Health Care). Initially, the dressing was changed every 3 days, later once a week. This could be an advantage compared to silver sulfadiazine and iodine, both of which require daily dressing changes. Risk of silver intoxication might be less pronounced than with silver sulfadiazine due to slower release of silver, but there is no study confirming this. ${ }^{51}$

There also exist a few reports on cost-efficient substances used in conservative treatment of GO in resource-limited areas. Nicoara et al described the conservative treatment of exomphalos with Manuka honey. It was used in five children; the authors saw no adverse effects. Median time to epithelialization was 63 days. ${ }^{52}$ Kouame et al described conservative treatment of GO by using dissodic $2 \%$ aqueous eosin in 173 patients over 15 years. Complete epithelialization was accomplished in $70 \pm 7$ days in 118 patients $(68.5 \%)$. Infection rate was $18 \%$, and mortality rate was $25.5 \%$. The average hospital stay was 20 days, and the parents continued the treatment at home with outpatient follow-up until complete epithelialization. The authors emphasize the low costs of the treatment. ${ }^{20}$

In a retrospective study, Mitul et al treated 27 patients with GO conservatively by applying gentian violet, four children died of overwhelming sepsis. Enteral feeding was started at days 3-7 of life; the skin closure was completed after 4-6 weeks. No adverse effects were seen, and the authors recommended this treatment because of its very low costs. ${ }^{21}$

\section{Conclusion}

The first reports of primary surgical closure of omphalocele, as well as the conservative approach in large omphaloceles, emerge around 1870-1900. Cunningham ${ }^{46}$ published one of the first review papers on exomphalos and assumed that there was a tendency to report only the successful outcomes in those early years. He considered the figures of $\mathrm{Gross}^{24}$ to give a more true picture. Gross reported a mortality of $37 \%$ 
in a series of patients accepted for surgery from 1940 to 1950 . A clear distinction between omphalocele and GO is not given in these early publications. Nonetheless, the surgical techniques developed and the clinical considerations undertaken by these early pioneers, such as whether primary, staged, or delayed repair would be the best option, can be considered fundaments of the current practice.

Since these early attempts to treat exomphalos, the emergence of a new medical field - neonatal intensive care - together with further development of surgical and conservative techniques, has led to major improvements in the care of patients with GO. However, the condition, often accompanied by other congenital malformations and/or pulmonary hypoplasia, is still associated with high mortality rates and significant morbidity in survivors. Although most clinicians are faced with the initial question whether a primary, staged, or delayed repair would be the right approach, the multitude of options in each group does show that no single technique has proven to be superior. The rarity of the malformation also makes it challenging to conduct studies comparing different approaches. Accordingly, each patient demands an individual approach. Is the infant stable enough to tolerate anesthesia and surgery? Can the herniated organs be reduced in one step? Is the omphalocele sac intact and robust enough to withstand an attempt of delayed repair? These are questions that have to be asked each time facing an infant with a GO (Figure 1).

There are few publications regarding short- and long-term outcomes in these patient groups. Peranteau et $\mathrm{al}^{53}$ reported systemic hypertension requiring antihypertensive medications in a subgroup of infants born with GO, considering it a potential comorbidity requiring attention. Abnormality in pulmonary function found in GO survivors at a mean age of 19.3 months included lung volume restriction, increased likelihood of airway responsiveness, and reduced respiratory system-specific compliance. ${ }^{54}$ As already mentioned, high rates of severe neurodevelopmental delays have been reported in survivors of GO. ${ }^{1}$ Not surprisingly, Danzer et al reported prolonged ventilator support, high-frequency oscillatory ventilation, tracheostomy placement, oxygen supplementation at day 30 of life, pulmonary hypertension, delayed enteral feeding, need for feeding tube, abnormal hearing screen, and prolonged hospitalization as predictors of lower neurodevelopmental scores at a median age of 24 months. ${ }^{55}$ Autism, associated with delays in cognitive and language outcomes, was suspected/confirmed in 13\% of the patients. Hypotonicity was found in $55 \%$ of survivors and was, together with delayed stage closure and older age at final repair, associated with motor dysfunction.
Reports suggesting neurodevelopmental impairment in more than half of GO survivors call for increased awareness of need for support and follow-up of this patient group beyond the first years of life. ${ }^{55}$ Moreover, further studies on outcome beyond early childhood are lacking.

Although sparse in amount, all studies on short- and longterm outcomes in GO survivors emphasize the importance of regular and standardized somatic and neurodevelopmental evaluation throughout childhood of these patient groups with the scope of identifying those who might benefit from early intervention, special education, and rehabilitation measures. ${ }^{1,54,55}$

\section{Disclosure}

The authors report no conflicts of interest in this work.

\section{References}

1. Danzer E, Gerdes M, D'Agostino JA, et al. Prospective, interdisciplinary follow-up of children with prenatally diagnosed giant omphalocele: short-term neurodevelopmental outcome. J Pediatr Surg. 2010; 45(4):718-723.

2. Pacilli M, Spitz L, Kiely EM, Curry J, Pierro A. Staged repair of giant omphalocele in the neonatal period. J Pediatr Surg. 2005;40(5):785-788.

3. Davis NM, Kurpios NA, Sun X, Gros J, Martin JF, Tabin CJ. The chirality of gut rotation derives from left-right asymmetric changes in the architecture of the dorsal mesentery. Dev Cell. 2008;15(1):134-145.

4. Thieme G. Developmental malformations of the fetal ventral body wall. Ultrasound Q. 1992;10(225):e65.

5. Barisic I, Clementi M, Häusler M, Gjergja R, Kern J, Stoll C. Evaluation of prenatal ultrasound diagnosis of fetal abdominal wall defects by 19 European registries. Ultrasound Obstet Gynecol. 2001;18(4):309-316.

6. Baird PA, MacDonald EC. An epidemiologic study of congenital malformations of the anterior abdominal wall in more than half a million consecutive live births. Am J Hum Genet. 1981;33(3):470-478.

7. Blazer S, Zimmer EZ, GoverA, Bronshtein M. Fetal omphalocele detected early in pregnancy: associated anomalies and outcomes. Radiology. 2004;232(1):191-195.

8. Charlesworth P, Ervine E, McCullagh M. Exomphalos major: the Northern Ireland experience. Pediatr Surg Int. 2009;25(1):77-81.

9. Ein SH, Langer JC. Delayed management of giant omphalocele using silver sulfadiazine cream: an 18-year experience. J Pediatr Surg. 2012; 47(3):494-500.

10. Montero FJ, Simpson LL, Brady PC, Miller RS. Fetal omphalocele ratios predict outcomes in prenatally diagnosed omphalocele. Am J Obstet Gynecol. 2011;205(3):284.e1-7.

11. Campos BA, Tatsuo ES, Miranda ME. Omphalocele: how big does it have to be a giant one? J Pediatr Surg. 2009;44(7):1474-1475. Author reply 1475.

12. Fawley JA, Peterson EL, Christensen MA, Rein L, Wagner AJ. Can omphalocele ratio predict postnatal outcomes? J Pediatr Surg. 2016; 51(1):62-66.

13. Lacey SR, Carris LA, Beyer AJ, Azizkhan RG. Bladder pressure monitoring significantly enhances care of infants with abdominal wall defects: a prospective clinical study. J Pediatr Surg. 1993;28(10):1370-1375.

14. Van Eijck FC, Aronson DA, Hoogeveen YL, Wijnen RM. Past and current surgical treatment of giant omphalocele: outcome of a questionnaire sent to authors. J Pediatr Surg. 2011;46(3):482-488.

15. Baerg JE, Thorpe DL, Sharp NE, et al. Pulmonary hypertension predicts mortality in infants with omphalocele. J Neonatal Perinatal Med. 2015;8(4):333-338.

16. Drack F, Mack A, Kistler W, Rogdo B. A giant omphalocele in a preterm infant: the conservative approach. BMJ Case Rep. 2014;2014: bcr2014204151. 
17. Feltman D, Stokes T, Kett J, Lantos JD. Is treatment futile for an extremely premature infant with giant omphalocele? Pediatrics. 2014;133(1):123-128.

18. Lee SL, Beyer TD, Kim SS, et al. Initial nonoperative management and delayed closure for treatment of giant omphaloceles. J Pediatr Surg. 2006; 41(11):1846-1849.

19. Kumar HR, Jester AL, Ladd AP. Impact of omphalocele size on associated conditions. J Pediatr Surg. 2008;43(12):2216-2219.

20. Kouame BD, Odehouri Koudou TH, Yaokreh JB, et al. Outcomes of conservative treatment of giant omphaloceles with dissodic $2 \%$ aqueous eosin: 15 years' experience. Afr J Paediatr Surg. 2014;11(2):170-173.

21. Mitul AR, Ferdous K. Initial conservative management of exomphalos major with gentian violet. J Neonatal Surg. 2012;1(4):51.

22. Suominen PK, Pakarinen MP, Rautiainen P, Mattila I, Sairanen H. Comparison of direct and intravesical measurement of intraabdominal pressure in children. J Pediatr Surg. 2006;41(8):1381-1385.

23. Schwartz MZ, Tyson KRT, Milliorn K, Lobe TE. Staged reduction using a silastic sac is the treatment of choice for large congenital abdominal wall defects. J Pediatr Surg. 1983;18(6):713-719.

24. Gross RE. A new method for surgical treatment of large omphaloceles. Surgery. 1948;24(2):277-292.

25. Schuster SR. A new method for the staged repair of large omphaloceles. Surg Gynecol Obstet. 1967;125(4):837-850.

26. Allen RG, Wrenn EL. Silon as a sac in the treatment of omphalocele and gastroschisis. J Pediatr Surg. 1969;4(1):3-8.

27. Nuchtern JG, Baxter R, Hatch EI. Nonoperative initial management versus silon chimney for treatment of giant omphalocele. J Pediatr Surg. 1995;30(6):771-776

28. Baird R, Gholoum S, Laberge JM, Puligandla P. Management of a giant omphalocele with an external skin closure system. J Pediatr Surg. 2010;45(7):E17-20

29. Hong AR, Sigalet DL, Guttman FM, Laberge JM, Croitoru DP. Sequential sac ligation for giant omphalocele. J Pediatr Surg. 1994;29(3):413-415.

30. Risby K, Jakobsen MS, Qvist N. Congenital abdominal wall defects: staged closure by dual mesh. J Neonatal Surg. 2016;5(1):2.

31. Brown MF, Wright L. Delayed external compression reduction of an omphalocele (DECRO): an alternative method of treatment for moderate and large omphaloceles. J Pediatr Surg. 1998;33(7):1113-1116.

32. Foglia R, Kane A, Becker D, Asz-Sigall J, Mychaliska G. Management of giant omphalocele with rapid creation of abdominal domain. JPediatr Surg. 2006;41(4):704-709.

33. Martin AE, Khan A, Kim DS, Muratore CS, Luks FI. The use of intraabdominal tissue expanders as a primary strategy for closure of giant omphaloceles. J Pediatr Surg. 2009;44(1):178-182.

34. De Ugarte DA, Asch MJ, Hedrick MH, Atkinson JB. The use of tissue expanders in the closure of a giant omphalocele. J Pediatr Surg. 2004; 39(4):613-615.

35. Morgan R, Hanna L, Lakhoo K. Management of giant omphalocele: a case series. Eur J Pediatr Surg. 2012;23(3):254-256.

36. Rijhwani A, Davenport M, Dawrant M, et al. Definitive surgical management of antenatally diagnosed exomphalos. J Pediatr Surg. 2005;40(3): 516-522.

37. Shawyer AC, Bailey KA, Cameron BH. The use of Alloderm for a giant omphalocele with a ruptured sac and inadequate skin coverage. J Pediatr Surg Case Rep. 2013;1(9):267-269.
38. Travassos D, van Eerde A, Kramer W. Management of a giant omphalocele with non-cross-linked intact porcine-derived acellular dermal matrix (strattice) combined with vacuum therapy. European J Pediatr Surg Rep. 2015;03(2):061-063.

39. Kapfer SA, Keshen TH. The use of human acellular dermis in the operative management of giant omphalocele. J Pediatr Surg. 2006;41(1):216-220.

40. Reilingh TSDV, Van Goor H, Charbon JA, et al. Repair of giant midline abdominal wall hernias: "components separation technique" versus prosthetic repair: interim analysis of a randomized controlled trial. World $J$ Surg. 2007;31(4):756-763.

41. Ramirez OM, Ruas E, Dellon AL. "Components separation" method for closure of abdominal-wall defects: an anatomic and clinical study. Plast Reconstr Surg. 1990;86(3):519-526.

42. van Eijck FC, de Blaauw I, Bleichrodt RP, et al. Closure of giant omphaloceles by the abdominal wall component separation technique in infants. J Pediatr Surg. 2008;43(1):246-250.

43. van Eijck FC, van Vlimmeren LA, Wijnen RM, et al. Functional, motor developmental, and long-term outcome after the component separation technique in children with giant omphalocele: a case control study. JPediatr Surg. 2013;48(3):525-532.

44. Kilbride KE, Cooney DR, Custer MD. Vacuum-assisted closure: a new method for treating patients with giant omphalocele. J Pediatr Surg. 2006; 41(1):212-215.

45. Grob M. Conservative treatment of exomphalos. Arch Dis Child. 1963; $38: 148-150$

46. Cunningham AA. Exomphalos. Arch Dis Child. 1956;31(156):144-151.

47. Mullins ME, Horowitz BZ. Iatrogenic neonatal mercury poisoning from mercurochrome treatment of a large omphalocele. Clin Pediatr (Phila). 1999;38(2):111-112.

48. Whitehouse JS, Gourlay DM, Masonbrink AR, et al. Conservative management of giant omphalocele with topical povidone-iodine and its effect on thyroid function. J Pediatr Surg. 2010;45(6):1192-1197.

49. Lewis N, Kolimarala V, Lander A. Conservative management of exomphalos major with silver dressings: are they safe? J Pediatr Surg. 2010; 45(12):2438-2439.

50. Pandey V, Gangopadhyay AN, Gupta DK, Sharma SP, Kumar V. Nonoperative management of giant omphalocele with topical povidoneiodine and powdered antibiotic combination: early experience from a tertiary centre. Pediatr Surg Int. 2014;30(4):407-411.

51. Almond S, Reyna R, Barganski N, Emran MA. Nonoperative management of a giant omphalocele using a silver impregnated hydrofiber dressing: a case report. J Pediatr Surg. 2010;45(7):1546-1549.

52. Nicoara CD, Singh M, Jester I, Reda B, Parikh DH. Medicated manuka honey in conservative management of exomphalos major. Pediatr Surg Int. 2014;30(5):515-520.

53. Peranteau WH, Tharakan SJ, Partridge E, et al. Systemic hypertension in giant omphalocele: an underappreciated association. J Pediatr Surg 2015;50(9):1477-1480.

54. Danzer E, Hedrick HL, Rintoul NE, Siegle J, Adzick NS, Panitch HB. Assessment of early pulmonary function abnormalities in giant omphalocele survivors. J Pediatr Surg. 2012;47(10):1811-1820.

55. Danzer E, Gerdes M, D’Agostino JA, et al. Patient characteristics are important determinants of neurodevelopmental outcome during infancy in giant omphalocele. Early Hum Dev. 2015;91(3):187-193.
Research and Reports in Neonatology

\section{Publish your work in this journal}

Research and Reports in Neonatology is an international, peer-reviewed, open access journal publishing original research, reports, editorials, reviews and commentaries on neonatal health. The manuscript management system is completely online and includes a very quick and fair peer-review system. Visit http://www.dovepress.com/testimonials.php to read real quotes from published authors. 